\title{
Time to end ageism in medical education
}

I n 1969, Dr. Robert Butler published a seminal article describing "another form of bigotry," which he termed "ageism." Ageism, he wrote, reflects "a personal revulsion to and distaste for growing old, disease [and] disability." At the time, Butler predicted that ageism would parallel racism as the great social issue of the coming decades. Over 40 years later, society has made great progress toward equality at many levels; is ageism the last frontier?

As a medical student, I am deeply troubled by the care being provided to older Canadians and concerned that trainees across the country are being inadequately prepared to meet the unique needs of our aging population. Ageism in medical education begins in the structuring of formal medical school curricula. In 2015, Canadians over the age of 65 will outnumber those younger than the age of 14 , yet only 5 of 17 medical schools in Canada have a formal geriatrics clinical rotation. ${ }^{2}$ By contrast, all Canadian medical schools have mandatory four- to six-week pediatrics rotations that involve analogous age-specific diagnostic and management considerations. ${ }^{2}$

Traditional medical pedagogy is also biased against the management of older patients. Despite the proliferation of the biopsychosocial model, medical teaching still emphasizes so-called "textbook" presentations: single conditions in cognitively intact patients that are amenable (and often reversible) to therapeutic or surgical management. ${ }^{3}$ These cases rarely contemplate frail older patients who suffer from complex medical, cognitive, functional and social comorbidities. Consequently, medical trainees fail to learn the sort of comprehensive approaches necessary to treat our older population.

Many of the values, attitudes and beliefs that clinical trainees internalize are learned not within the formal curriculum but through a more latent "hidden curriculum." ${ }^{4}$ The latter curriculum

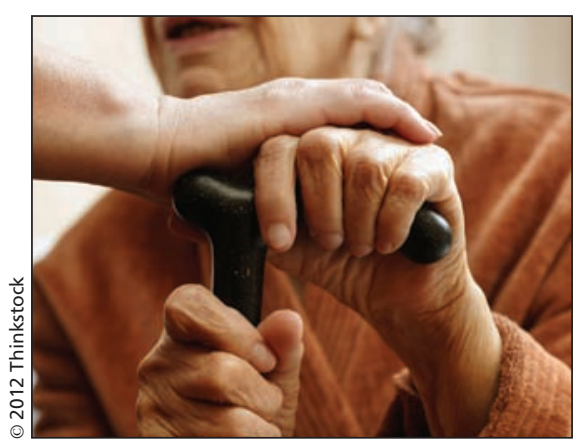

concerns itself with the enculturation of medical students into the larger profession, and I am concerned that ageism is present in this process.

When older patients with multiple comorbidities are admitted to Canadian hospitals with atypical clinical presentations, many are given vague diagnoses such as "acopia" (failure to cope). ${ }^{3}$ These admissions are commonly referred to as "social," justifying decisions that these are "nonmedical" patients who would be better served by other professionals., ${ }^{3,5}$ Rather than receiving comprehensive assessments and appropriate investigations, older patients are often met with ageist therapeutic nihilism. ${ }^{3}$ In any other (younger) patient population, these actions would be grounds for professional negligence.

Medical students are not blind to these processes; disarmed by a lack of preclinical geriatrics education, they quickly learn to adopt this behaviour and turn their focus to more "medical" (younger) patients. ${ }^{3}$ Clinical trainees begin to see older patients as sources of frustration and antagonism, and like their senior colleagues, they perceive these individuals as impediments to clinical efficiency and medical education. ${ }^{4}$ These disparaging attitudes likely contribute to the difficulty Canadian geriatric training programs have recruiting trainees to the specialty and the resulting crucial deficiency of geriatricians practising in Canada. ${ }^{6,7}$

To combat overt and latent biases alike, leaders in academic medicine must spearhead sweeping changes in medical education. Unquestionably, this process should begin with the eradication of ageism - a zero-tolerance policy should be mandated with offenders being reprimanded as they would be for prejudicing patients based on gender, race, religion or sexuality. Second, medical schools and postgraduate medical education programs must restructure curricula so that training actually reflects demographic imperatives. Medical schools should establish core geriatrics learning blocks in the preclinical years and mandatory clerkship rotations. Postgraduate trainees, both medical and surgical, should be encouraged to complete rotations in geriatrics to further develop the unique skills required to care for the frail older adult.

Finally, I call on all medical educators to lead a transformation in the way care of the older patient is presented to junior trainees. This could be promoted, for example, by featuring geriatric syndromes in "morning reports" and "case rounds" with equal prominence to the more favoured acute and rare conditions. Geriatric medicine must be viewed as the complex, intellectually stimulating and vital discipline that it is. ${ }^{3}$

Since the 1969 publication of Butler's article, medicine has prided itself in the many preventative and therapeutic interventions for conditions like heart disease, stroke and cancer that have prolonged Canadian lives by an additional 10 years. ${ }^{5}$ The profession must now take equal pride in learning to care for our older adults.

\section{Nathan Stall BSc}

Fourth-year medical student

Schulich School of Medicine and

Dentistry

Western University

London, Ont.

For references, see Appendix 1, available at www.cmaj.ca/lookup/suppl/doi:10.1503 /cmaj.112179/-/DC1

CMAJ 2012. DOI:10.1503/cmaj.112179 